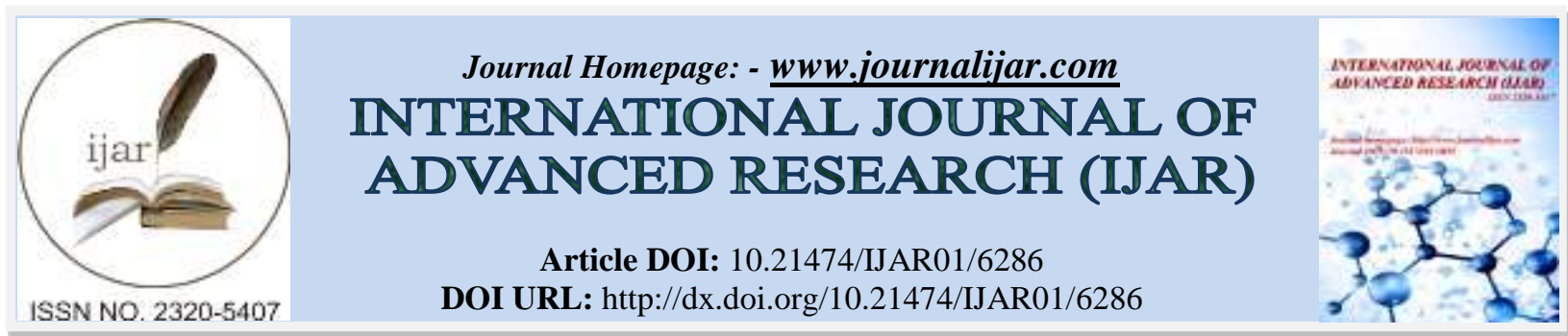

RESEARCH ARTICLE

\title{
USEFULNESS OF THE PEDIATRIC INDEX OF MORTALITY 2 IN PREDICTING MORTALITY RATE IN BENHA UNIVERSITY PEDIATRIC INTENSIVE CARE UNIT.
}

\author{
Hesham Abdul Aziz Elghaiaty, Ahmad Ata Sobeih and Eman Abd Errahim Bayoumy.
}

Pediatric Department, Faculty of Medicine, Benha University, Egypt.

\section{Manuscript Info}

Manuscript History

Received: 12 November 2017

Final Accepted: 14 December 2017

Published: January 2018

Key words:-

Pediatric Index of Mortality 2,

Mortality, Pediatric Intensive Care Unit.

\begin{abstract}
Background: little is known about the exact causes of death, and the impact of general risk factors that may complicate the course of critically ill patients. Scoring systems for use in ICUS allow an assessment.

Aim of the study: To evaluate the usefulness of PIM2 score in predicting the outcome (mortality rate) in PICU in Benha university hospitals.

Methods: This prospective study was conducted on 113 patients admitted to PICU in Benha University Hospitals in pediatric department over a period of six months. All patients aged more than one month up to less than sixteen years old. Pediatric index of mortality 2 was scored for all patients within an hour of admission to PICU using a structured data collection form and then compared with outcome which recorded as death or discharge.

Results: Data were collected prospectively as a cohort study upon 11 children admitted to PICU in Benha University hospitals during a six months period. The outcome of the 113 patients included in the study was 77 survivors and 36 non-survivors. Observed death rate was $(31.9 \%)$ and the predicted mortality rate by PIM2 score was $38.1 \%$. So, the standardized mortality ratio was 0.84 signifying overestimation of mortality rate and/or good performance of our unit. PIM2 discriminated between death and survival well with area under the ROC curve was 0.73 and cutoff value at $(-2.99)$ which is a good discrimination and calibrated well ( $p=0.88$ in non survivors and 0.83 in survivors).

Conclusion: PIM2 applied in our PICU was significantly correlated to mortalities as PICU outcome and showed adequate discriminatory function and well calibrated for the case mix of patients in PICU of Benha University hospitals. So, it can be used as a good predictor of mortality in PICUS.
\end{abstract}

Copy Right, IJAR, 2018,. All rights reserved.

\section{Introduction:-}

One pediatric population of special interest is critically-ill children requiring intensive care services, since these children are at an increased risk of death [1]. Mortality reduction is the fundamental aim of a pediatric intensive care unit (PICU), a physician's accuracy in estimating mortality risk for patients admitted to intensive care unit is largely subjective [2]. Scoring systems are used to predict the outcome of patients admitted to intensive care units [3]. 
Moreover they are used to evaluate the performance of ICUs [4]. The mortality rate of patients admitted to Intensive Care Units is a widely adopted outcome indicator, and in children it was reported to vary from $3.8 \%$ to $13 \%$ in North and South America and in Europe [5-8]. Because of case-mix variability, comparisons of mortality between different Units, and in the same Unit over time, must be adjusted for the severity of patient illness at admission. To this end, severity-scoring systems specific for the pediatric population have been developed [9]. Many illness severity scoring systems are being used for predicting the outcome of patients admitted to pediatric intensive care units (PICU) and this has been constantly validated [10]. Scoring systems such as the Pediatric Risk of Mortality (PRISM) score and Pediatric Index of Mortality (PIM) are widely used in pediatric intensive care. These are third generation scoring systems that allow assessment of the severity of illness and mortality risk adjustment in heterogenous groups of patients in an objective manner, enabling conversion of these numbers into a numerical mortality risk based on logistic regression analysis [11].

Subjects And Methods:-

This prospective observational study was conducted on a ten beds tertiary care PICU and included 113 patients. All patients aged more than one month up to less than sixteen years old who were admitted to PICU in pediatric department in Benha university hospitals during a 6-months period, requiring intensive care services. Inclusion criteria were: patients admitted with medical or surgical problem with one or more system failure and patients staying alive for at least 8 hours after admission. Readmissions to the PICU during the same hospitalization was analyzed as separate patients because each admission presented as a separate opportunity for an outcome. Exclusion criteria were: patients aged above 16 years old. Patients died within 8 hours after admission. Patients who stayed less than 24 hours. Either these patients were wrongly admitted in PICU without clear indication of major risk or these patients have least risk factors that with treatment by simple measure were referred to general word to complete their treatment strategy.

\section{Methods:-}

All children included in this study were undergone detailed history taking, thorough clinical examination on admission, recording all patients data including name, age, sex, admission type (elective or emergent), referring speciality, diagnosis, failing organ system, duration of ICU stay (DOS), all variables of PIM2 scores which were elective admission to PICU, recovery post procedure, cardiac bypass, high-risk diagnosis, low-risk diagnosis, no response of pupils to bright light (>3 mm and both fixed), mechanical ventilation (at anytime during the first hour in PICU), systolic blood pressure ( $\mathrm{mmHg}$ ), base excess $(\mathrm{mmHg})$ (arterial or capillary blood), and $\mathrm{FiO} 2 / \mathrm{PaO} 2$ (mmHg) were recorded. Then pediatric index of mortality 2 was scored within an hour of admission to PICU using a structured data collection form. PIM 2 score consists of ten variables. Yes or no response for these variables were scored as 1 or 0 . These were entered into the system (www.sfar.org/scores2/pim22.html) for calculation of predicted mortality rate. The system computes the predicted mortality rate based on standard methods using logistic regression equation $[\underline{20}, 4 \underline{5}]$. The patient outcome recorded and then the ratio of observed to predicted mortality (standardized mortality ratio (SMR) were calculated for the set of patients.

Statistical analysis:-

The collected data were tabulated and analyzed using SPSS version 16 soft ware (SpssInc, Chicago, ILL Company), MedCalc 16.1 sofware. Categorical data were presented as number and percentages while quantitative data were expressed as mean \pm standard deviation, median, Inter Quartile Range (IQR) and range. Chi square test $\left(\mathrm{X}^{2}\right)$, or Fisher's exact test (FET) and McNemer's test were used to analyze categorical variables. Quantitative data were tested for normality using Kolomogrov Smirnove test, using Student "t " if normally distributed, or Man Whitney $U$ test and Spearman's correlation ( rho ), if not normally distributed. ROC curve was used to determine cutoff value of PIM2 score with optimum sensitivity and specificity. Binary logistic regression model was used to design an equation for predicted mortality from PIM2 score. The accepted level of significance in this work was stated at 0.05 ( $P<0.05$ was considered significant $)$.

\section{Results:-}

Data were collected prospectively as a cohort study upon 113 children admitted to PICU in Benha University hospitals during a 6-months period. The outcome of the 113 patients included in the study was 77 survivors and 36 non-survivors. figure 1 shows that observed death rate was $(31.9 \%)$. The Mean \pm SD age of included cases was $39.1 \pm$ 43.0 months (table 1) and 56.6\% of them were male. The 3 most common reasons for these admissions were CNS emergencies (36.3\%), respiratory emergencies (25.7\%), and cardiac emergencies (12.4\%) (figure 2). Our study showed that 
the observed mortality rate was $31.9 \%$ and the predicted mortality rate by PIM2 score was $38.1 \%$ (table 5). Results showed significant difference between survivors and non survivors according to the response of pupil to light and showed highly significant difference between survivors and non survivors regarding mean values of $\mathrm{FiO} 2$, $\mathrm{FiO} 2 / \mathrm{PaO} 2 \%$ and using $\mathrm{MV} 1 \mathrm{H}$ and significant difference in base excess but no significant difference in $\mathrm{PaO} 2$ $(\mathrm{mmHg})$ (table 2$)$ and highly significant difference in high risk diagnosis. Our study demonstrated that the percentage of male sex in survivors and non-survivors was $57.1 \%$ and $55.6 \%$ respectively. But there was no significant difference between survivors and non-survivors regarding sex $(\mathrm{p}=0.87)$. This was in agreement with PIM 2 score that not consider any score for sex difference. Regarding duration of stay, mean value in survivors and non survivors was 6.84 and 9.75 respectively as shown in table 3 and statistical analysis showed significant difference, it was longer in non survivors. In our study statistical analysis (using scater plot) showed positive correlation between PIM2 score and risk of mortality (figure 4),Fio2 and duration of stay, and a negative correlation between PIM2 score and SBP and base excess. To validate any mortality score system, 3 points must be discussed, the standardized mortality ratio (SMR), discrimination and calibration. In our study, the actual mortality rate was $31.9 \%$ and the predicted mortality rate by PIM2 score was $38.1 \%$. So, the standardized mortality ratio was 0.84 signifying overestimation of mortality rate and/or good performance of our unit (table 5). Mortality discrimination was quantified by calculating the area under the ROC curve (a plot of sensitivity vs. specificity). The area under the ROC curve (AUC) provides a parameter for discriminatory performance of the model. In our study, area under the curve was 0.73 which is good (figure 3) and the sensitivity of PIM2 score at -2.99 cut-off was $69.4 \%$, and the specificity was $77.9 \%$ and the negative predictive value of the PIM2 score at -2.99 cut-off was found to be $84.5 \%$ and positive predicted point was $59.5 \%$ (table 4). The most accepted method for measuring calibration is the goodness-of-fit test proposed by Hosmer and Lemeshow. The value of $\mathrm{p}$ was required to be greater than 0.05 for good calibration of the model [12]. In our study, PIM2 showed good calibration $(\mathrm{p}=0.88)$ in non survivors and $(\mathrm{p}=0.83)$ in survivors (table $6)$.

Figures and Tables:-

\section{$\%$ of outcome among the studied sample}

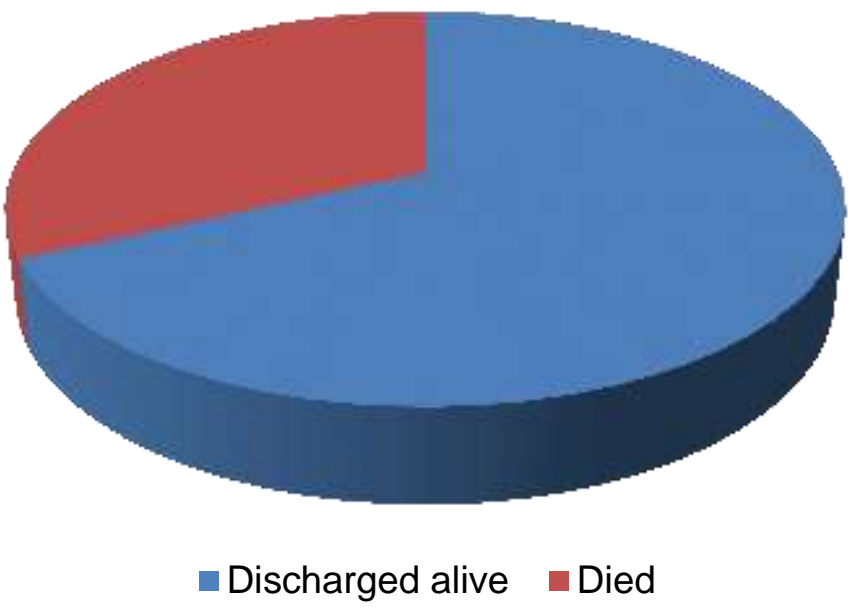

Fig 1:- Pie chart shows the observed death rate which was 31.9\% 


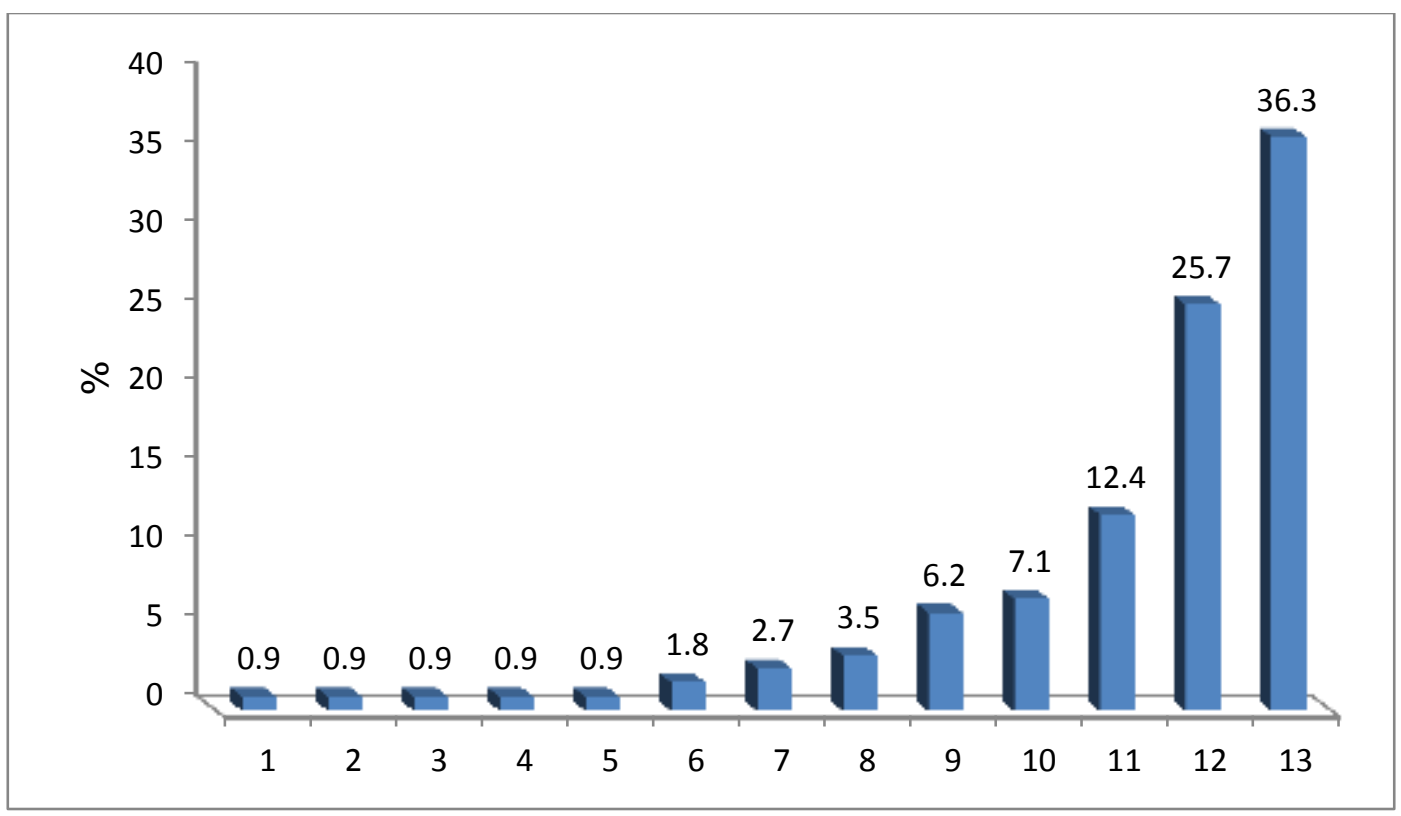

Fig. (2):- Shows the percent of diagnostic categories

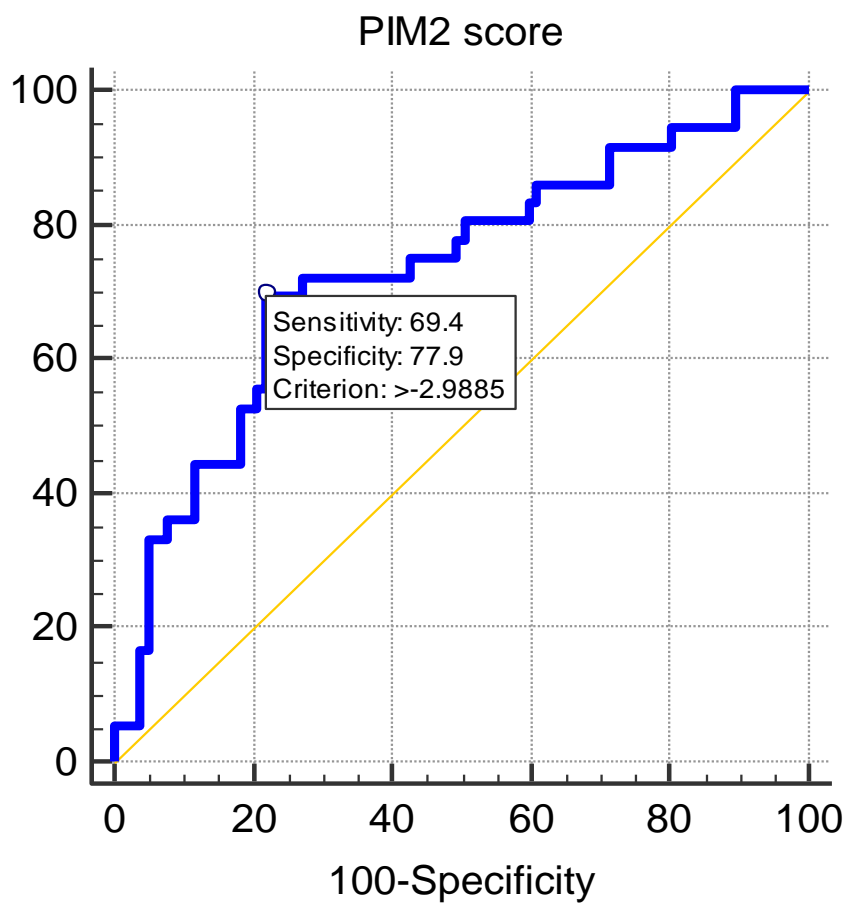

Fig (3):- ROC curve for the validity and predictivity of PIM2 score in prediction of mortality 

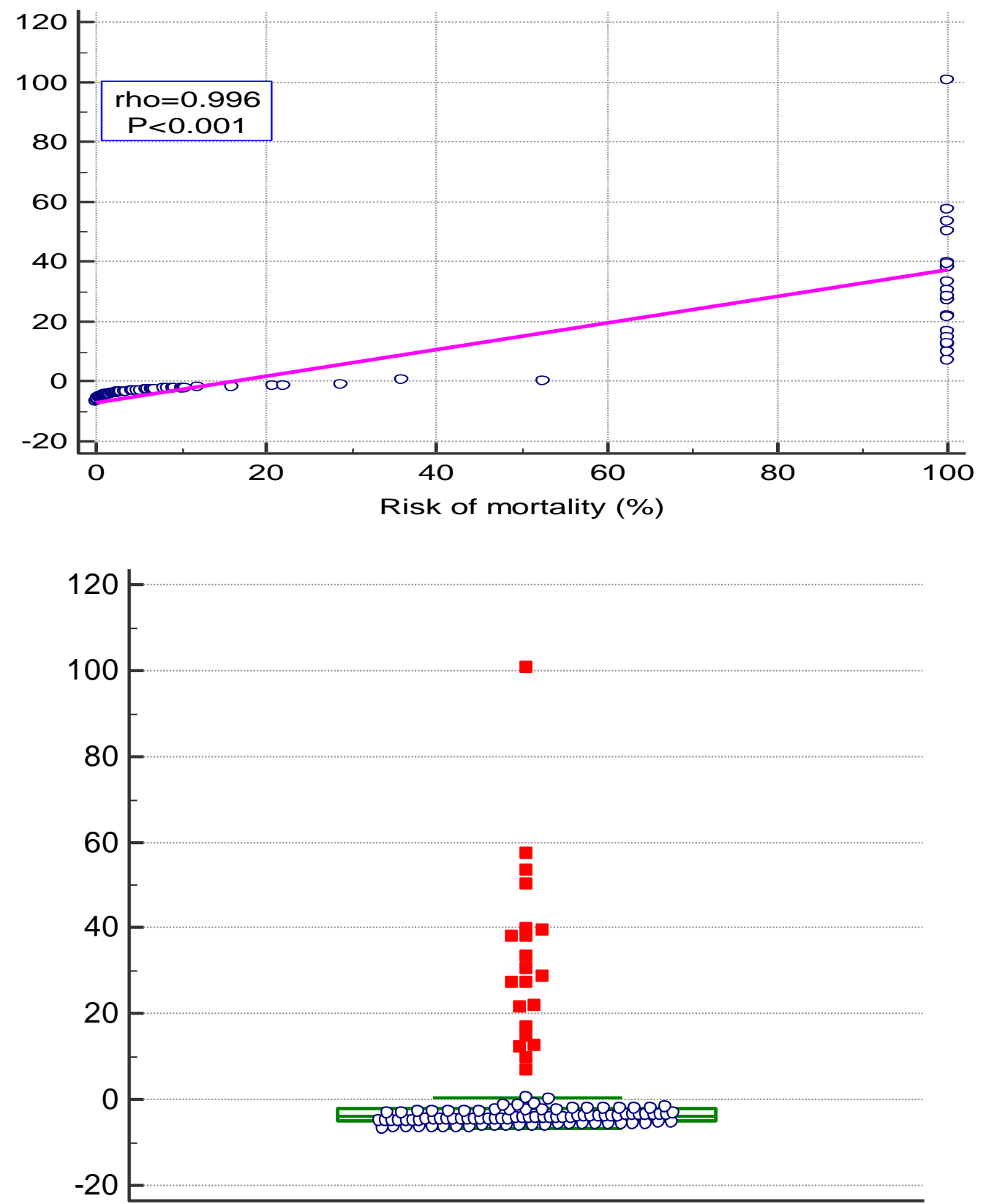

Fig 5:- Box plot for the median and IQR $\left(25^{\text {th }}-75^{\text {th }}\right.$ percentile $)$ of PIM2 score.

Mean value of PIM2 score was $2.64 \pm 16.92$

Median value of PIM2 $=-3.80$

Table 1:- Socio-demographic characters of the studied sample

\begin{tabular}{|l|l|l|l|}
\hline Variable & No. $(\mathbf{N}=113)$ & \% (100\%) \\
\hline \multirow{2}{*}{ Sex } & Male & 64 & 56.6 \\
\cline { 2 - 4 } & Female & 49 & 43.4 \\
\hline Age (months) & Mean \pm SD & Minimum & Maximum \\
\hline
\end{tabular}


Table 2:- Comparison between survivors and non survivors regarding some variables

\begin{tabular}{|c|c|c|c|c|c|c|}
\hline \multirow[t]{2}{*}{ Variable } & \multicolumn{2}{|c|}{$\begin{array}{c}\text { Discharged alive } \\
(\mathrm{N}=77)\end{array}$} & \multicolumn{2}{|c|}{$\begin{array}{l}\text { Died } \\
(\mathrm{N}=36)\end{array}$} & \multirow[t]{2}{*}{$\mathbf{Z}_{\mathrm{MWU}}$} & \multirow[t]{2}{*}{$\mathbf{P}$} \\
\hline & Mean & $\pm \mathrm{SD}$ & Mean & $\pm \mathrm{SD}$ & & \\
\hline $\mathrm{FiO}_{2}$ & 6.3 & 20.19 & 21.6 & 32.88 & 3.23 & $0.001(\mathrm{HS})$ \\
\hline PaO2(mmHg) & 75.4 & 62.93 & 56.0 & 26.33 & 1.33 & $0.18(\mathrm{NS})$ \\
\hline FiO2/PaO2\% & 10.6 & 37.24 & 44.7 & 75.62 & 3.32 & $0.001(\mathrm{HS})$ \\
\hline BaseExcess (mmol/L) & -5.98 & 7.02 & -13.65 & 28.3 & 2.22 & $0.026(\mathrm{~S})$ \\
\hline PIM2 score & -1.11 & 11.33 & 10.68 & 23.22 & 3.94 & $<0.001(\mathrm{HS})$ \\
\hline
\end{tabular}

Table 3:- Correlation between PIM2 score and the studied variables

\begin{tabular}{|l|c|c|}
\hline \multirow{2}{*}{ Variable } & \multicolumn{2}{|c|}{ PIM2 score } \\
\cline { 2 - 3 } Age & rho & P \\
\hline HR & 0.109 & 0.25 \\
\hline RR & 0.120 & 0.21 \\
\hline Temperature & -0.001 & 0.99 \\
\hline SBP & -0.065 & 0.49 \\
\hline DBP & -0.237 & $0.011(\mathrm{~S})$ \\
\hline Duration of stay & -0.178 & 0.06 \\
\hline FIO & 0.305 & $0.001(\mathrm{HS})$ \\
\hline PaO2(mmHg) & 0.674 & $<0.001(\mathrm{HS})$ \\
\hline FiO2/PaO2\% & -0.112 & 0.24 \\
\hline Base Excess (mmol/L) & 0.678 & $<0.001(\mathrm{HS})$ \\
\hline Risk of mortality & -0.454 & $<0.001(\mathrm{HS})$ \\
\hline
\end{tabular}

Table 4:- Cutoff point of PIM2 score

\begin{tabular}{|l|c|c|c|c|c|c|c|c|}
\hline Cutoff point & Sens $\%$ & Spec $\%$ & PPV\% & NPV\% & Aacuracy\% & AUC & 95\%CI & P \\
\hline $\begin{array}{l}\text { PIM2 score } \\
\geq \\
-2.99\end{array}$ & $69.4 \%$ & $77.9 \%$ & $59.5 \%$ & $84.5 \%$ & $75.2 \%$ & 0.73 & $0.63-0.84$ & $<0.001$ \\
& & & & & & & & (HS) \\
\hline
\end{tabular}

Table 5:- Comparing observed and predicted mortality

\begin{tabular}{|c|c|c|c|c|c|}
\hline & & & \multicolumn{2}{|c|}{ Observed mortality } & \multirow[t]{2}{*}{ Total } \\
\hline & & & Survived & Died & \\
\hline \multirow{4}{*}{$\begin{array}{l}\text { Predicted } \\
\text { Mortality }\end{array}$} & \multirow[t]{2}{*}{ Survived } & Count & 59 & 11 & 70 \\
\hline & & $\%$ within Outcome & $76.6 \%$ & $30.6 \%$ & 61.9 \\
\hline & \multirow[t]{2}{*}{ Died } & Count & 18 & 25 & 43 \\
\hline & & $\%$ within Outcome & $23.3 \%$ & $69.4 \%$ & 38.1 \\
\hline \multirow{2}{*}{\multicolumn{2}{|c|}{ Total }} & Count & 77 & 36 & 113 \\
\hline & & $\%$ within Outcome & $100.0 \%$ & $100.0 \%$ & $100.0 \%$ \\
\hline
\end{tabular}

Mc Nemer's test was used $\quad \mathrm{P}=0.26$ (NS)

Table 6:- Calibration of PIM2 score

\begin{tabular}{|c|c|c|c|c|c|c|}
\hline PIM2 score & $\begin{array}{c}\text { Observed } \\
\text { death }\end{array}$ & $\begin{array}{c}\text { Expected } \\
\text { death }\end{array}$ & $\mathrm{X}^{2} \& P$ & $\begin{array}{c}\text { Observed } \\
\text { survival }\end{array}$ & $\begin{array}{c}\text { Expected } \\
\text { survival }\end{array}$ & $\mathbf{X}^{2} \& P$ \\
\hline$>0$ & 12 & 15 & & 11 & 8 & \multirow{4}{*}{$\begin{array}{c}0.85 \& \\
0.83(\mathrm{NS})\end{array}$} \\
\hline 0 to -2 & 11 & 14 & $\begin{array}{c}0.81 \\
\& 0.88(\mathrm{NS})\end{array}$ & 9 & 6 & \\
\hline-3 to -5 & 10 & 9 & & 36 & 37 & \\
\hline$<-5$ & 3 & 5 & & 21 & 19 & \\
\hline & 36 & 43 & & 77 & 70 & \\
\hline
\end{tabular}




\section{Discussion:-}

Scoring systems are means to quantify clinical states that are difficult to summarize by other subjective or objective means. These systems are especially valuable in the ICUs, where subjective impressions of clinical states, severity of illness, and risk of mortality are highly variable [13].Scoring systems involve using appropriately weighted demographic, physiological, and clinical data collected on the infant to calculate a score that quantifies its morbidity [14]. Risk-adjustment tools (scoring systems) that predict death in PICUs have become established in the past 20 years. The physiologic stability index, published in 1984 [15], has been updated twice, using data from North American PICUs, and renamed, first as the Pediatric Risk of Mortality (PRISM) [16], and more recently as PRISM III [17]. PRISM III currently provides the risk-adjustment tool for the United States based pediatric intensive care unit evaluations (PICUEs) system, which provides comparative reports to participating units under a licensing arrangement [18]. The alternative to the PRISM family of tools is the Pediatric Index of Mortality (PIM) [19], which was updated recently to PIM2 [20]. PIM was published in 1997, based on admissions to PICUs in Australia and in the United Kingdom. PIM 2 was published in 2003 and included 15191 admissions from 10 PICUs in Australia and New Zealand and 4 PICUs in the United Kingdom [21]. It is the most popular used to predict mortality in PICUs [22]. PIM2 estimates mortality risk from data readily available at the time of PICU admission and is therefore suitable for continuous monitoring of the quality of pediatric intensive care units [20]. In our study, data were collected prospectively from the records of 113 children admitted to PICU in pediatric department in Benha University hospitals during a 6-months period. The Mean \pm SD age of included cases was $39.1 \pm 43.0$ months and $56.6 \%$ of them were male. The 3 most common reasons for these admissions were CNS emergencies (36.3\%), respiratory emergencies (25.7\%), and cardiac emergencies (12.4\%). In contrast to study done by Atiaa et al.(2013) showing respiratory emergencies (33\%), CNS emergencies (24\%), and cardiac emergencies (19\%). Our study showed that the observed mortality rate was $31.9 \%$ and the predicted mortality rate by PIM2 score was $38.1 \%$ which is considerably higher compared to various studies. The mortality rates observed by Tibby and Murdoch [23], Leteurtre [24], Chamberlain [25] and Kendirli [26] were 7.8\%, 10\%, 8\%, 12.2\% respectively. But lower than study done in Zagazig University by Atiaa [27] which showed that observed mortality rate was $49.5 \%$ and predicted mortality was $39.5 \%$, and also lower than a study done in India which found that the observed death rate was $46.21 \%(\mathrm{n}=55)$. The death rate predicted by PIM2 score was $68.00 \%(n=82)$ by Gandhi [28]. In Italy a study found that overall observed mortality was $4.4 \%$, compared to $6.4 \%$ expected mortality by Atti [29]. There are 3 main suggested reasons for this high mortality. Firstly, Lack of priority of admission, as we are admitting hopeless cases in our PICU. Health care economies demand that health care resources provided should be used in a cost effective and efficient way such that the quality of care is not jeopardized [30]. Secondly, lack of special transportation team. During transport by ambulance, we haven't any special team for transport and this carry a lot of risk during that journey. Orr et al., [31] in their study signify the importance of the transport team as a major factor in the outcome of cases and show that the mortality rate among patients transported by non specialized teams was more than among patients transported by specialized team for transport (23\% versus 9\%). Thirdly, inefficient standard of care. We have ten beds in our PICU, this number is not sufficient to meet the needs of severity of illness in major three governorates that we serve. Our PICU provides one nurse for two patients $(1: 2), 2$ resident doctor and 1 specialist who are present at any time and one consultant on call for 24 hours. On studying the demographic characters of the two patient groups (survivors and non-survivors), the mean age for survivors was $42.3 \pm 45.6$ months and for non-survivors was $32.3 \pm 36.6$ months. The statistical analysis showed a non significant difference between both groups $(\mathrm{p}=0.87)$. Our study demonstrates that the percentage of male sex in survivor and non-survivor was $57.1 \%$ and $55.6 \%$ respectively. No significant difference between survivors and non-survivors regarding sex $(\mathrm{p}=0.87)$. This is in agreement with PIM 2 score that not consider any score for sex difference.

Also, this finding is in agreement with the study of Lopez [1] who stateed that the majority of patients admitted in the PICU for five years were males (57.5\%). At the end of their study, they demonstrate that there is no difference between both genders regarding outcomes. In our study, of the 36 non-survivors, 16 (44.4\%) were mechanically ventilated. The statistical analysis showed highly significant difference between survivors and non-survivors regarding mechanical ventilation. This is in agreement with PIM2 score that includes mechanical ventilation among its variables. The high mortality rate in the mechanically ventilated group can be explained by the known hazards of mechanical ventilation including barotraumas, mechanical ventilation induced pneumonia, sudden arrest and insufficient gas exchange results as well. This is in agreement with the study done by Kendirl [26] in which the mortality rate of mechanically ventilated patients was $58.3 \%$. This is in contrast to Silva [32] who stated that the mortality rate in mechanically ventilated patients was $19.7 \%$ only. This lower incidence of mortality is due to early referral of admitted cases and the different diagnostic categories of patients. Regarding response of pupils to light, $13.9 \%$ of non-survivor had no response of pupil to light. The statistical analysis showed significant difference 
between survivors and non-survivors as regard response of pupils. This is in agreement with PIM2 score that includes response of pupils among its variables. Regarding duration of stay, mean value in survivors and non survivors was 6.84 and 9.75 respectively, and statistical analysis showed significant difference, it was longer in non survivors. Regarding the diagnosis, $25 \%$ of non-survivors had high risk diagnosis and the statistical analysis showed significant difference between survivors and non survivors as regard high risk diagnosis. Regarding vital signs in our study, mean temperature at time of admission was $37.3 \pm 0.81^{\circ} \mathrm{C}$ with no significant statistical difference between survivors and non-survivors. This result is in contrast to the study done by El Nawawy [33] and Atiaa [27] who demonstrated that mean temperature of $37.5^{\circ} \mathrm{C}$ and $37,6^{\circ} \mathrm{C}$ with highly significant statistical difference between survivors and non survivors. About systolic and diastolic pressures of admitted cases in our PICU, there is no significant statistical difference between survivors and non survivors where mean systolic blood pressure of both groups was $104 \pm 20.5 \mathrm{mmHg}$ and mean diastolic blood pressure of both groups was $57.6 \pm 16.5 \mathrm{mmHg}$. This is due to the wide difference of age presentation among the studied group with the variation of clinical diagnostic group. This result is in agreement with the study done by El Nawawy [33] and Atiaa [27] who demonstrated non significant difference between the blood pressure of both groups. The mean heart rate was $137 \pm 28$ bpm with no significant difference between both groups. The mean respiratory rate was $41.0 \pm 12$ with no significant difference between both groups. In our study, statistical analysis (using scater plot) showed positive correlation between PIM2 score and risk of mortality, Fio2 and duration of stay. But showed negative correlation between PIM2 score and SBP and Base excess. To validate any mortality score system, 3 points must be discussed; The standardized mortality ratio (SMR), discrimination and calibration. The mortality was standardized for case mix using the standardized mortality ratio. The SMR is calculated by dividing the actual mortality rate by the predicted mortality rate of the study population. If SMR less than 1, it means an overestimation of mortality in the PICU by the score and/or better performance by the PICU compared to the PICUs that developed the scoring system. If SMR is more than 1, the reverse is true.

In our study, the actual mortality rate was $31.9 \%$ and the predicted mortality rate by PIM 2 score was $38.1 \%$, so the standardized mortality ratio was 0.84 signifying overestimation of mortality rate and/or good performance of our unit.

In a study done in Pakistan to compare the performance of 3 scoring systems (PRISM, PELOD and the PIM2) at a general PICU, Qureshi [12] found that SMR for PIM2 was 1.4 which is in contrast to our result.

Also Thukral [34] found similar results while evaluating PRISM and PIM2 in a developing country setting PIM2 underestimated the mortality where SMR was 1.57. Also Atiaa [27] found that PIM2 score was 39,5\% and SMR was 1.25 signifying underestimation of mortality rate and/or poor performance of their unit. And a study from India reported that SMR was 1.57 by Slater [20].

On the other hand, several authors found an opposite results as Hariharan [4] who found that the standardized mortality ratio of PIM2 was 0.86. In Argentina, Eulmesekian [35] found that the standardized mortality ratio for PIM2 was 0.85. In Japanese PICU, Imamura [36] found that the standardized mortality was 0.77. Atti [29] in Italy found that Standardized mortality ratio was 0.7. Again, these results mean an overestimation of mortality or better performance by these PICUs compared to the PICUs that developed PIM2 and this is in agreement with our study.

Discrimination is the ability of a test to calculate a higher mortality probability among non-survivors than survivors across the whole group. In other words, discrimination is important while distinguishing the outcome either survival or morbidity among the admitted patients [12].

Mortality discrimination was quantified by calculating the area under the ROC curve (a plot of sensitivity vs. specificity). The area under the ROC curve (AUC) provides a parameter for discriminatory performance of the model. In our study, area under the curve was( $(0.73)$ which is good.

This AUC value is lower than those revealed by many authors . Slater [20] who developed PIM2 score revealed that AUC of PIM2 was 0.9. Also, Brady [18] had performed a study in the United Kingdom to validate PIM2 performance at 18 pediatric intensive care units from all the United Kingdom and data were collected on 10,197 patients. This study revealed an AUC of 0.9. In Pakistan, Qureshi [12] found that AUC for PIM2 was 0.88. 
In Zagazig University, Atiaa [27] found that AUC for PIM2 was 0.75. In Al Fayoum University, Bekhit [37] found that AUC for PIM2 was 0.75. Hariharan [38] showed that PIM2 score had good discrimination with area under ROC being 0.82 in a PICU of a developing country. PIM2 score was a good predictor of mortality in this study and is comparable to the results by Slater [20] and Eulmesekian [35] who showed that PIM2 discriminated between death and survival well with area under the ROC curve was 0.90, and 0.87 from Spain by Prieto Espunes [39], and in Italy by Atti [29] found PIM2 discrimination was fair (AUC 0.79).

In a study done in India the sensitivity of PIM2 score at 99.8 cut-off was $98.2 \%$, it can be used as a screening tool for assessing severity of illness of children admitted in PICU. The negative predictive value of the PIM2 score at 99.8 cut-off was found to be $97.7 \%$. This helps identify children who have more chances of survival, which in turn helps in counseling parents of sick children admitted to PICU. The low specificity (65.6\%) of PIM2 score denotes that not all patients with high predicted death rate may die. This reflects that effective interventions at PICU reduce mortality of those who have high predicted death rate at the time of admission, and, thereby, indicate good performance of PICU. Positive predicted point was $71.1 \%$ in the study done by Sangareddi[28], while in our study the sensitivity of PIM2 score at -2.99 cut-off was $69.4 \%$, and the specificity was $77.9 \%$ and the negative predictive value of the PIM2 score at -2.99 cut-off was found to be $84.5 \%$ and positive predicted point was $59.5 \%$. Calibration measures the correlation between the predicted outcomes and actual outcome over the entire range of risk prediction. In other words, calibration is more important while comparing expected and observed outcome at various intervals of severity [12]. The most accepted method for measuring calibration is the goodness-of-fit test proposed by Hosmer and Lemeshow. The value of $\mathrm{p}$ was required to be greater than 0.05 for good calibration of the model [12]. In our study, PIM2 shows well calibration ( $\mathrm{p}=0.88$ in non survivors and 0.83 in survivors), in contrast to Atiaa [27] who showed a moderate calibration $(\mathrm{p}=0.07)$. Other studies showed better calibration like Slater [20] who reported excellent calibration ( $p=0.17)$. Also, Brady [18] and Qureshi [12] reported the same findings $(p=0.32$ and $p=0.29$, respectively). A study from Italy applied PIM2 and found that it calibrates well $(\mathrm{X} 2=4.92, \mathrm{df}=8, \mathrm{p}=0.26) \mathrm{done}$ byWolfler [40]. Nether Land calibrated the model and found to be acceptable $(\mathrm{X} 2=4.92, \mathrm{df}=8$, $\mathrm{p}=0.77)$ done by Slater [41]. Also in Spain, the model calibrated well $(\mathrm{X} 2=4.87, \mathrm{df}=8, \mathrm{p}=0.85)$ done by Prieto Espunes [39]. Studies from developing countries also reported good calibration of PIM2 score, such as a study from Trinidad (X2=5.61, $\mathrm{df}=8, \mathrm{p}=0.69)$ done by Hariharan [4]., and a study from Barbados $(\mathrm{X} 2=5.64, \mathrm{df}=7, \mathrm{p}=0.58)$ done by Hariharan [38], and in Al Fayoum University a study done by Bekhit [37] found (H-L X2 $=1.410, \mathrm{df}=8$, p=0.9) well calibration, while in Italy by Atti [29] Calibration was less satisfactory (114.7 vs. 53; p < 0.001). Difference in results of discrimination, calibration and SMR among different studies has been attributed to various factors like poor performance of medical system in developing countries where resources are more limited [12], different case mix [42], disease pattern [43] and failure of the scoring system equation to model the actual situation accurately [44]. In our study, PIM2 score on day of admission showed significant positive correlation with risk of mortality with acceptable discrimination ability (area under ROC curve 0.73 ), and good calibration $(\mathrm{p}=0.88)$.

\section{Conclusion:-}

PIM2 scoring system shows adequate discriminatory function and well calibrated for the case mix of patients in PICU of Benha University. It can be used as beneficial tool for evaluation of risk adjusted mortality.

\section{References:-}

1. Lopez AM, Tilford JM, Anand KJ, et al (2006): Variation in pediatric intensive care therapies and outcomes by race, gender, and insurance status. Pediatr Crit Care Med 2006; 7:2-6.

2. Teres D, Lemeshow S. (1993) :Using severity measures to Clin.; 9:543-554.

3. Hariharan S, Zbar A.(2006)::Risk scoring and prediction of outcomes in perioperative and surgical intensive care patients ? a review. Curr Surg.; 63:226-36.

4. Hariharan S, Merritt-Charles L, Chen D (2007): Risk-adjusted outcome evaluation in a multidisciplinary intensive care unit. West Indian Med J; 56(3):240-5.

5. Kipper DJ, Piva JP, Garcia PC, et al., (2005): Evolution of the medical practices and modes of death on pediatric intensive care units in southern Brazil. Pediatr Crit Care Med, 6:258-263

6. Althabe M, Cardigni G, Vassallo JC, et al., (2003): Dying in the intensive care unit: collaborative multicenter study about forgoing life-sustaining treatment in Argentine pediatric intensive care units. Pediatr Crit Care Med 2003, 4:164-169.

7. Garros D, Rosychuk RJ, Cox PN. Circumstances surrounding end of life in a pediatric intensive care Unit. Pediatrics. 2003;13:e371. doi: 10.1542/peds.112.5.e371. 
8. Martinot A, Grandbastien B, Leteurtre Set al., (1998): No resuscitation orders and withdrawal of therapy in French paediatric intensive care Units. Groupe Francophone de Reanimation etd' Urgences Pediatriques. ActaPaediatr, 87:769-773.

9. Randolph AG (1997): Pediatric index of mortality (PIM): Do we need another paediatric mortality predictions score? Intensive Care Med 1997, 23(2):141-142.

10. Marik PE, Varon J.(1999): Severity scoring and outcome assessment. Computerized predictive models and scoring systems. Crit Care Clin;15:633-46

11. Van Keulen JG, Polderman KH, Gemke RJBJ(2005): Reliability of PRISM and PIM scores in paediatric intensive care. Arch Dis Child 2005; 90:211-214.

12. Qureshi AU, Ali AS and Ahmad TM (2007): Comparison of three prognostic scores (PRISM, PELOD and PIM 2) at pediatric intensive care unit under Pakistani circumstances. JA yub Med Coll Abbottabad; 19(2):49-53.

13. Marcin JP, Pollack MM (2000): Review of the methodologies and applications of scoring systems in neonatal and pediatric intensive care. Pediatr Crit Care Med 2000; 1:20-27.

14. Kadivar M, Sagheb S, Bavafa F, Moghadam L and Eshrati B (2007) : Neonatal Mortality Risk Assessment in a Neonatal Intensive Care Unit (NICU). Iran J Ped , 17 (4): 325-31.

15. Yeh TS, Pollack MM, Ruttimann UE, et al. (1984): Validation of physiology stability index for use in critically ill infants and children. Pediatric Res; 18: 445-51.

16. Pollack MM, Ruttimann UE, Getson PR(1988): Pediatric risk of mortality (PRISM) score. Crit Care Med 1988; 16:1110-1116.

17. Pollack MM, Patel KM, Ruttimann UE(1996): PRISM III: An updated Pediatric Risk of Mortality score. Crit Care Med. 1996; 24: 743-752

18. Brady AR, Harrison D, Black S, Jones S, Rowan K, Pearson G, Ratcliffe J, Parry GJ (2006) : Assessment and optimization of mortality prediction tools for admissions to pediatric intensive care in the United kingdom. Pediatrics; 117(4):733-42.

19. Shann F, Pearson G, Slater A, et al(1997): Paediatric index of mortality (PIM): a mortality prediction model for children in intensive care. Intensive Care Med 1997; 23:201-207.

20. Slater A, Shann F, et al, (PIM Study Group) (2003):. PIM2: a revised version of the Paediatric Index of Mortality. Intensive Care Medicine 2003; 29: 278-285.

21. Pearson G A, Stickley J and Shann E (2001): Calibration of the pediatric index of mortality in UK pediatric intensive care units. Arch Dis Child; 84: 125-8.

22. Choi KM, Ng DK, Wong SF, et al., (2005):Assessment of the Pediatric Index of Mortality (PIM) and the Pediatric Risk of Mortality (PRISM III) score for the prediction of mortality in a pediatric intensive care unit in Hong Kong. Hong Kong Med; 11: 97-113.

23. Tibby SM, Taylor D, Festa M, Hanna S, Hatherill M, Jones G, Habibi P, Durward A, Murdoch IA(2002): A comparison of three scoring systems for mortality risk among retrieved intensive care patients Arch Dis Child 2002; 87:421-425.

24. Leteurtre S, Leclerc F, Wirth J, et al (2004): Can generic pediatric mortality scores calculated 4 hours after admission be used as inclusion criteria for clinical trials? Critical Care, 8: 185-193.

25. Chamberlain J, Patel K and Pollack MM (2005): The Pediatric Risk of Hospital Admission Score: A secondgeneration severity-of-illness score for pediatric emergency patients. Pediatrics; 115(2):388-95.

26. Kendirli T, Kavaz A, Yalaki Z, et al.(2006): Mechanical ventilation in children. Turk J of Pediatr ; 48: 323-27.

27. Atiaa T, Morsy SM and Ahmed ME.(2013): Performance of pediatric index of mortality II in Zagazig Univeristy pediatric intensive care unit. Thesis under supervision of Tarek Atiaa and Said M. Morsy, pediatric Department, Faculty of Medicine, Zagazig University.

28. J, Sangareddi S, Varadarajan P., et al., (2013): Pediatric index of mortality 2 score as an outcome predictor in pediatric Intensive Care Unit in India. Department of Pediatric Intensive Care Unit, Institute of Child Health and Hospital for Children, Madras Medical College, Chennai, Tamil Nadu, India. Indian J Crit Care Med. 2013 Sep-Oct; 17(5): 288-29

29. Atti M L C, Cuttini M, Rava L et al .,(2013): Performance of the pediatric index of mortality 2 (PIM2) in cardiac and mixed intensive care units in a tertiary children's referral hospital in Italy. BMC Pediatr. 2013; 13: 100.

30. Fiser DH (1996): Outcome analysis, MC Rogers. Nichols DG, editor. Textbook of Pediatric Intensive Care. 3rd ed. Baltimor, USA: Wlliams\&Wilkins; 1663-9.

31. Orr RA, Felmet KA, Han Y, McCloskey KA, Dragotta MA, Bills DM, Kuch BA and Watson RS (2009): Pediatric specialized transport teams are associated with improved outcomes. Pediatrics; 124(1):40-8. 
32. Silva DC, Shibata AR, Farias JA, Troster EJ.(2009): How is mechanical ventilation employed in a pediatric intensive care unit in Brazil? Clinics (Sao Paulo) ; 64(12):1161-6.

33. El-Nawawy AA, Kamel MI and and Sad EF (2006): Evaluation of the ability of PRISMII and PIM2 scores to predict outcome of patients admitted to Alexandria University PICU. Thesis under supervision of Ahmed A. El-Nawawy and Mohamed I. Kamel, Pediatric Department, Faculty of medicine, Alexandria University

34. Thukral A, Lodha R , Irshad M , Arora NK(2006): Performance of Pediatric Risk of Mortality (PRISM), Pediatric Index of Mortality (PIM), and PIM2 in a pediatric intensive care unit in a developing country. Pediatr Crit Care Med. ;(4):356-61.

35. Eulmesekian PG, Perez A, Minces PG, Ferrero H,(2007): Validation of pediatric index of mortality 2 (PIM2) in a single pediatric intensive care unit of Argentina. Pediatr Crit Care Med.;8:54-7

36. Imamura T, Nakagawa S, Goldman RD and Fujiwara T (2012): Validation of pediatricindex of mortality2 (PIM2) in a single pediatric intensive care unit in Japan. Intensive CareMed.; 38(4):649-54.

37. Bekhit OEM, Algameel AA and Eldash HH (2014): Application of Pediatric Index oF Mortality Version 2 In Pediatric Intensive Care Unit in an African developing country. Thesis under supervision of Osama El Sayed Mohamed Bekhit and Al Kassem Ahmed Algameel. Pediatric Department, Faculty of Medicine, AlFayoum University, Alfayoum, Egypt.

38. Hariharan S, Krishnamurthy K, Grannum D(2011): Validation of Pediatric Index of Mortality-2 scoring system in a pediatric intensive care unit, Barbados. J Trop Pediatr. 2011;57:9-13.

39. Prieto Espunes S, Lopez-Herce Cid J, Rey Galan C, et al (2007): Prognostic indexes of mortality in pediatric intensive care units. An Pediatr (Barc). 2007; 66:345-50.

40. Wolfler A, Silvani P, Musicco M, Ida Salvo I, (2007): Italian Pediatric Sepsis Study (SISPe) Group. Pediatric Index of Mortality 2 score in Italy: a multicenter, prospective, observational study. Intensive Care Med. 2007 Aug;33(8):1407-13.

41. Slater A, Shann F (2004), for the Anzics Paediatric Study Group. The suitability of the Pediatric Index of Mortality (PIM), PIM2, the Pediatric Risk of Mortality (PRISM), and PRISM III for monitoring the quality of pediatric intensive care in Australia and New Zealand. Pediatr Crit Care Med. 2004 Sep;5(5):447-54.

42. Pappachan JV, Millar B, Bennett ED and Smith GB(1999): Comparison of outcome from intensive care admission after adjustment for case mix by the APACHE III prognostic system. Chest; 115:802-10.

43. Markgraf R, Deutschinoff G, Pientka L and Scholten T (2000): Comparison of acute physiology and chronic health evaluations II and III and simplified acute physiology score II: a prospective cohort study evaluating these methods to predict outcome in a German interdisciplinary intensive care unit. Crit Care Med; 28:26-33.

44. Livingston BM, MacKirdy FN, Howie JC, Jones R, Norrie JD (2000): Assessment of the performance of five intensive care scoring models within a large Scottish database. Crit Care Med, 28:1820-7.

45. Di Carlo J, Frankel LR. Scoring systems and predictors of mortality. In: Kliegman RM, Behrman RE, Jenson HB, Stanton BF, editors. Nelson Textbook of Pediatrics. 18th ed. Philadelphia: Saunders Publishers; 2007. p. 387. 